\title{
Optimal Decisions for a Fuzzy Two-Echelon Supply Chain
}

\author{
Qingfeng Song, ${ }^{1}$ Kai Shi, ${ }^{2}$ Sheng Lin, ${ }^{2}$ and Guangping $\mathrm{Xu}^{2}$ \\ ${ }^{1}$ School of Science, Tianjin Chengjian University, Tianjin 300384, China \\ ${ }^{2}$ School of Computer Science and Communication Engineering, Tianjin University of Technology, Tianjin 300384, China
}

Correspondence should be addressed to Kai Shi; shikai0229@tju.edu.cn

Received 9 September 2013; Revised 14 December 2013; Accepted 31 December 2013; Published 19 February 2014

Academic Editor: M. De la Sen

Copyright (C) 2014 Qingfeng Song et al. This is an open access article distributed under the Creative Commons Attribution License, which permits unrestricted use, distribution, and reproduction in any medium, provided the original work is properly cited.

\begin{abstract}
This paper discusses the optimal decisions of pricing and selling effort for a two-echelon supply chain with uncertain consumer demands, manufacturing costs, and selling costs. In order to maximize the $\alpha$-optimistic value of the profits, based on different market structures, one centralized decision model and three decentralized decision models are developed, and the corresponding analytical equilibrium solutions are obtained using the game-theoretical approach. The results illustrate that no matter what decision case is, the optimal retail and wholesale prices in the case of considering selling effort are, respectively, larger than those of no selling effort; the optimal profits of the manufacturer, the retailer, and the whole supply chain system in the case of considering selling effort are, respectively, larger than those of no selling effort except for the profit of the retailer in the case that the manufacturer plays the leader's role. Finally, one numerical example is presented, which illustrates the effectiveness of the proposed models.
\end{abstract}

\section{Introduction}

With the rapid development of technology and economy, powerful retailers are booming worldwide (e.g., Walmart, Carrefour, etc.). To grasp the market opportunities to win, retailers take action actively, where selling effort is the most effective one. Despite the powerful influence on the world economy, their promotion policies and strategies stimulate great research interest among academics. Several papers have concentrated on selling effort described above for singleperiod supply chain with deterministic or random demand in recent years. Lariviere and Porteus [1] illustrated the importance of selling effort on the consumer demands. Taylor [2] studied the problem of coordination for a reverse supply chain, where selling effort has an influence on the consumer demands. Cachon and Lariviere [3] investigated the problem of revenue-sharing contract for a supply chain with influence of selling effort. Mesak et al. [4] researched the problem of advance selling and showed its significance on revenue and pricing in the field of supply chain. Krishnan et al. [5] studied coordinate contracts for decentralized supply chains with retailers' ex ante- and ex postpromotional selling effort. Dash $\mathrm{Wu}$ [6] investigated the bargaining problem for a supply chain with competing manufacturers and competing retailers, where selling effort has an important influence on consumer demand. We add to this growing literature of channel studies by modeling price and selling effort decision for a manufacturer and a retailer in a two-echelon supply chain with uncertain parameters in the sense of fuzziness.

Many uncertain factors are embedded in the supply chain, such as customs' demand, manufacturing cost, selling cost, and inventory cost. These uncertainties may affect the effectiveness of supply chain management and should not be neglected. Quite a few of researchers have concentrated on the randomness aspect of uncertainty and developed a lot of stochastic modeling techniques based on certain probability assumption, where uncertain parameters are typically modeled by probability distributions, for example, $[7,8]$. A. H. L. Lau and H.-S. Lau [9] declared that uncertain parameter forecast based on expert knowledge and judgments seemed to be more appropriate, when there was little or no historical data available and probability distribution might be neither simply available nor accurately estimated. Fuzzy theory, originally introduced by Zadeh [10] and perfected by B. Liu and Y.-K. Liu [11], provides an effective way to deal with optimization problems with uncertainty of subjective vagueness, where the uncertainty should be described as a fuzzy variable [12]. In fact, fuzzy theory has gradually become a powerful 
mathematical tool to deal with supply chain problems under incomplete information, for instance, coordination [13], performance evaluation [14], and pricing decision $[15,16]$. Chuu [17] built a group decision-making model of flexibility in supply chain management and adopt a fuzzy linguistic approach to determine the degree of system flexibility. Wei and Zhao [18] considered the optimal pricing decision problem of a fuzzy closed-loop supply chain with retail competition. Zhao et al. $[19,20]$ studied the optimal pricing problem of two substitutable products for supply chains with fuzzy uncertainty. Wang et al. [21] developed a joint replenishment and delivery (JRD) model with stochastic demand under fuzzy backlogging cost, fuzzy minor ordering cost, and fuzzy inventory holding cost.

Thus far, to the best of our knowledge, no research has been found to study the two-echelon supply chain decision problems with selling effort in a fuzzy environment. For this reason, this paper is to study the two-echelon supply chain with uncertainties associated with the custom demand, manufacturer cost, and selling cost, which are characterized as fuzzy variables [11]. Our main interest is to investigate how the manufacturer and the retailer make their own pricing decisions about wholesale prices, retail prices, and selling efforts in a fuzzy uncertain environment. We also focus on the market power balance between the channel members (i.e., the manufacturer and the retailer) and its effects on the equilibrium prices, selling efforts, and profits. Four scenarios are discussed, including a centralized case and three decentralized cases; namely, the manufacturer has more bargaining power, the retailer has more bargaining power, and each part in the system has equal bargaining power. Motivated by [22, 23], four chance-constrained programming models will be built to maximize the $\alpha$-optimistic value of the profits of both the manufacturer and the retailer, and the analytical equilibrium solutions are obtained by adopting the game-theoretical approach.

The rest of this paper is organized as follows. Section 2 presents model description and notations. The chanceconstrained programming models of one centralized decision and three decentralized decisions are established in Section 3. One numerical example is given to illustrate the effectiveness of the proposed models in Section 4. Finally, conclusions are made in Section 5.

\section{Problem Description}

Consider a two-echelon supply chain with a manufacturer and a retailer, where the former makes one product with cost $c$ and then wholesales the product with wholesale price $w$ to the retailer, who in turn retails it with retail price $p$ and selling effort $e$ to a customer. Since the decision makers have little or no historical data on manufacturing $\operatorname{cost} c$, we should describe it as a fuzzy variable.

The demand function is adopted as a linear one, which decreases with retail price but increases with selling effort; that is,

$$
D(p, e)=a-b p+k e
$$

where $a$ represents the market base, $b$ and $k$ are price and effort elastic coefficient, respectively, which denote the measure of the responsiveness of the product's market demand to its retail price and the retailer's selling effort. The cost of the retailer's selling effort is assumed as

$$
g(e)=l e^{2},
$$

where $l$ represents effort cost coefficient. We assume that the parameters $a, b, k, l$, and $c$ are independent nonnegative fuzzy parameters.

Since the wholesale price is $w$ and the retail price is $p$, the marginal profit of the retailer $m=p-w$. The respective profit functions of the manufacturer and retailer can be expressed as

$$
\begin{gathered}
\pi_{m}(w, p, e)=(w-c) D(p, e), \\
\pi_{r}(w, p, e)=(p-w) D(p, e)-g(e),
\end{gathered}
$$

and the profit function of the whole supply chain in the centralized decision case can be described as

$$
\begin{aligned}
\pi_{c}(p, e) & =\pi_{m}(w, p, e)+\pi_{r}(w, p, e) \\
& =(p-c) D(p, e)-g(e) .
\end{aligned}
$$

The chance-constrained programming is adopted to formulate the optimization problem, where both the manufacturer and the retailer make the pricing or selling effort decisions to achieve the highest profit with a given confidence level subjected to some chance constraints [24]. That is, the markup $p-c$ and the consumers demand $D(p, e)$ are nonnegative in the real world; thus, $\operatorname{Cr}\{p-c<0\}=0$ and $\operatorname{Cr}\{a-b p+k e<$ $0\}=0$.

\section{Main Results}

3.1. Centralized Decision (CD) Model. In order to evaluate channel decision under different decision cases, the centralized decision case should be firstly examined, where there is one entity (one integrated firm: including both the manufacturer and the retailer) that aims to optimize the whole system performance, so both the manufacturer's and the retailer's decisions are fully coordinated. In the centralized decision supply chain, the wholesale price $w$ is viewed as an inner transfer price, and the decision maker will choose proper retail price $p$ and selling effort $e$ to optimize the optimistic value with a given confidence level $\alpha \in(0,1]$ subjected to some chance constraints, which can be formulated as

$$
\begin{array}{ll}
\underset{(p, e)}{\max } \max _{\bar{\pi}_{c}} \bar{\pi}_{c} \\
\text { s.t. } & \operatorname{Cr}\left\{(p-c)(a-b p+k e)-l e^{2} \geq \bar{\pi}_{c}\right\} \geq \alpha \\
& \operatorname{Cr}\{a-b p+k e<0\}=0 \\
& \operatorname{Cr}\{p-c<0\}=0,
\end{array}
$$

where $\bar{\pi}_{c}$ is the threshold value of the profit of the whole supply chain and the second and third constraints represent that the customers' demand and the marginal profit are nonnegative. 
Theorem 1. Let $p_{c}^{*}, e_{c}^{*}$, and $\bar{\pi}_{c}^{*}$ be the optimal retail price, selling effort, and system profit of the CD scenario; then

$$
\begin{gathered}
p_{c}^{*}=\frac{2\left(a_{\alpha}^{U}+b_{\alpha}^{L} c_{\alpha}^{L}\right) l_{\alpha}^{L}-\left(k_{\alpha}^{U}\right)^{2} c_{\alpha}^{L}}{4 b_{\alpha}^{L} l_{\alpha}^{L}-\left(k_{\alpha}^{U}\right)^{2}}, \\
e_{c}^{*}=\frac{\left[a_{\alpha}^{U}-b_{\alpha}^{L} c_{\alpha}^{L}\right] k_{\alpha}^{U}}{4 b_{\alpha}^{L} l_{\alpha}^{L}-\left(k_{\alpha}^{U}\right)^{2}}, \\
\bar{\pi}_{c}^{*}=\left(p_{c}^{*}-c_{\alpha}^{L}\right)\left(a_{\alpha}^{U}-b_{\alpha}^{L} p_{c}^{*}+k_{\alpha}^{U} e_{c}^{*}\right)-l_{\alpha}^{L}\left(e_{c}^{*}\right)^{2},
\end{gathered}
$$

provided that $\operatorname{Cr}\{Z-c<0\}=0,4 b_{\alpha}^{L} l_{\alpha}^{L}>\left(k_{\alpha}^{U}\right)^{2}$, and $\operatorname{Cr}\{a<$ $\left.b Z-k\left(k_{\alpha}^{U}\left[a_{\alpha}^{U} l_{\alpha}^{L}-b_{\alpha}^{L} c_{\alpha}^{L} l_{\alpha}^{L}+2 c_{\alpha}^{L}\left(k_{\alpha}^{U}\right)^{2}-2 c_{\alpha}^{L}\right] / l_{\alpha}^{L}\left[2 b_{\alpha}^{L} l_{\alpha}^{L}-\left(k_{\alpha}^{U}\right)^{2}\right]\right)\right\}=$ 0 , where $Z=\left(\left(a_{\alpha}^{U}+b_{\alpha}^{L} c_{\alpha}^{L}\right) l_{\alpha}^{L}+2 c_{\alpha}^{L}\left(k_{\alpha}^{U}\right)^{2}\right) /\left(2 b_{\alpha}^{L} l_{\alpha}^{L}-\left(k_{\alpha}^{U}\right)^{2}\right)$.

Proof. For each feasible solution $(p, e), \bar{\pi}_{c}$ should be the maximum value that the integrated-firm's profit $\pi_{c}(p, e)$ achieves with at least credibility $\alpha$ [25]. Thus, model (6) is equivalent to the following model (9), where the integrated firm tries to maximize the $\alpha$-optimistic value of its profit $\pi_{c}(p, e)$ by choosing proper $p$ and $e$; that is,

$$
\begin{array}{ll}
\max _{(p, e)} & {\left[(p-c)(a-b p+k e)-l e^{2}\right]_{\alpha}^{U}} \\
\text { s.t. } & \operatorname{Cr}\{a-b p+k e<0\}=0 \\
& \operatorname{Cr}\{p-c<0\}=0,
\end{array}
$$

where the subscript and the superscript ${ }_{\alpha}^{U}$ denote the $\alpha$ optimistic value and ${ }_{\alpha}^{L}$ denotes the $\alpha$-pessimistic value.

As fuzzy variables $a, b, k$, and $l$ are nonnegative and independent with each other, according to [26], we have

$$
\left[\pi_{c}(p, e)\right]_{\alpha}^{U}=\left(p-c_{\alpha}^{L}\right)\left(a_{\alpha}^{U}-b_{\alpha}^{L} p+k_{\alpha}^{U} e\right)-l_{\alpha}^{L} e^{2} .
$$

The first and second partial derivatives of (10) with respect to $(p, e)$ can be obtained as

$$
\begin{gathered}
\frac{\partial\left[\pi_{c}(p, e)\right]_{\alpha}^{U}}{\partial p}=-2 b_{\alpha}^{L} p+k_{\alpha}^{U} e+a_{\alpha}^{U}+b_{\alpha}^{L} c_{\alpha}^{L}, \\
\frac{\partial\left[\pi_{c}(p, e)\right]_{\alpha}^{U}}{\partial e}=k_{\alpha}^{U} p-2 l_{\alpha}^{U} e-k_{\alpha}^{U} c_{\alpha}^{L}, \\
\frac{\partial^{2}\left[\pi_{c}(p, e)\right]_{\alpha}^{U}}{\partial p^{2}}=-2 b_{\alpha}^{L}, \quad \frac{\partial^{2}\left[\pi_{c}(p, e)\right]_{\alpha}^{U}}{\partial e^{2}}=-2 l_{\alpha}^{L}, \\
\frac{\partial^{2}\left[\pi_{c}(p, e)\right]_{\alpha}^{U}}{\partial p \partial e}=\frac{\partial^{2}\left[\pi_{c}(p, e)\right]_{\alpha}^{U}}{\partial e \partial p}=k_{\alpha}^{U} .
\end{gathered}
$$

If $4 b_{\alpha}^{L} l_{\alpha}^{L}-\left(k_{\alpha}^{U}\right)^{2}>0$, the Hessian matrix is negative definite and $\left[\pi_{c}(p, e)\right]_{\alpha}^{U}$ is a concave function of $(p, e)$. By setting (11) equal to zero and solving for $(p, e)$, the optimal strategy can be obtained as in (7). Substituting (7) into (10), the maximal profit value of the integrated firm can be obtained as in (8).
Corollary 2. If the selling effort is not considered, model (9) degenerates into

$$
\begin{array}{ll}
\max _{p} & {\left[\pi_{c}(p)\right]_{\alpha}^{U}=[(p-c)(a-b p)]_{\alpha}^{U}} \\
\text { s.t. } & \operatorname{Cr}\{a-b p<0\}=0 \\
& \operatorname{Cr}\{p-c<0\}=0 .
\end{array}
$$

The optimal retail price $p_{c}^{* *}$ and system profit $\bar{\pi}_{c}^{* *}$ in model (13) which corresponded to $p_{c}^{*}$ in (7) and $\bar{\pi}_{c}^{*}$ in (8) are

$$
\begin{gathered}
p_{c}^{* *}=\frac{a_{\alpha}^{U}+b_{\alpha}^{L} c_{\alpha}^{L}}{2 b_{\alpha}^{L}}, \\
\bar{\pi}_{c}^{* *}=\left(p_{c}^{* *}-c_{\alpha}^{L}\right)\left(a_{\alpha}^{U}-b_{\alpha}^{L} p_{c}^{* *}\right) .
\end{gathered}
$$

In the following, three decentralized decision supply chain cases are discussed, where the manufacturer and the retailer are independent with each other, and both of them would make decisions with the purposes of maximizing the $\alpha$-optimistic value of their own profits, respectively. The three different two-echelon channel structures includes the following (1) the manufacturer has more bargaining power; (2) the retailer has more bargaining power; and (3) each part in the system has an equal bargaining power.

3.2. Manufacturer Leader Stackelberg (MS) Model. The second scenario arises in the markets where the retailer's size is smaller compared to the manufacturer's. In this case, the manufacturer is the leader and the retailer is the follower, and the timing of the game proceeds as follows: firstly, the manufacturer chooses the wholesale price $w$; then, the retailer observes the wholesale price, fixes a retail price $p$, and chooses selling effort $e$; finally, the retailer and the manufacturer obtain their profits, respectively. The two-echelon MS model can be formulated as

$$
\begin{array}{ll}
\max _{w} & \max _{\bar{\pi}_{m}} \bar{\pi}_{m} \\
\text { s.t. } & \operatorname{Cr}\left\{(w-c)\left(a-b p^{*}(w)+k e^{*}(w)\right) \geq \bar{\pi}_{m}\right\} \geq \alpha \\
& \operatorname{Cr}\{w-c<0\}=0 \\
& \left(p^{*}, e^{*}\right) \text { solves } \\
& \max _{(p, e)} \quad \max _{\bar{\pi}_{r}} \bar{\pi}_{r} \\
\text { s.t. } \quad & \operatorname{Cr}\left\{(p-w)(a-b p+k e)-l e^{2} \geq \bar{\pi}_{r}\right\} \geq \alpha \\
& \operatorname{Cr}\{a-b p+k e<0\}=0 \\
& p \geq w,
\end{array}
$$

where $\bar{\pi}_{m}$ and $\bar{\pi}_{r}$ are the threshold values of the manufacturer's profit and the retailer's profit, respectively. 
Theorem 3. In the MS model, given the wholesale price $w$ made earlier by the manufacturer, the retailer's optimal decisions $p^{*}(w)$ and $e^{*}(w)$ are

$$
\begin{gathered}
p^{*}(w)=\frac{2 a_{\alpha}^{U} l_{\alpha}^{L}+\left(2 b_{\alpha}^{L} l_{\alpha}^{L}-\left(k_{\alpha}^{U}\right)^{2}\right) w}{4 b_{\alpha}^{L} l_{\alpha}^{L}-\left(k_{\alpha}^{U}\right)^{2}}, \\
e^{*}(w)=\frac{\left(a_{\alpha}^{U}-b_{\alpha}^{L} w\right) k_{\alpha}^{U}}{4 b_{\alpha}^{L} l_{\alpha}^{L}-\left(k_{\alpha}^{U}\right)^{2}},
\end{gathered}
$$

under condition that $4 b_{\alpha}^{L} l_{\alpha}^{L}>\left(k_{\alpha}^{U}\right)^{2}$ and $\operatorname{Cr}\left\{a+\left(\left(a_{\alpha}^{U}\left(k k_{\alpha}^{U}-\right.\right.\right.\right.$ $\left.\left.\left.\left.2 b l_{\alpha}^{L}\right)+\left(b\left(k_{\alpha}^{U}\right)^{2}-2 b b_{\alpha}^{L} L_{\alpha}^{L}-k b_{\alpha}^{L} k_{\alpha}^{U}\right) w\right) /\left(4 b_{\alpha}^{L} k_{\alpha}^{U}-\left(b_{\alpha}^{U}\right)^{2}\right)\right)<0\right\}=0$.

Proof. For each fixed feasible solution $(w, p, e), \bar{\pi}_{r}$ and $\bar{\pi}_{m}$ should be the maximum values that the retailer's profit function $\pi_{r}(w, p, e)$ and the manufacturer's profit function $\pi_{m}(w, p, e)$ can achieve with at least credibility $\alpha$. Thus, model (15) is equivalent to the following model (17) where the retailer and the manufacturer try to maximize the $\alpha$ optimistic values of their respective profits by choosing proper retailing price, selling effort, and wholesale price:

$$
\begin{array}{cl}
\max _{w} \quad\left[(w-c)\left(a-b p^{*}(w)+k e^{*}(w)\right)\right]_{\alpha}^{U} \\
\text { s.t. } \quad \operatorname{Cr}\{w-c<0\}=0 \\
\left(p^{*}, e^{*}\right) \text { solves } \\
\max _{(p, e)} \quad\left[(p-w)(a-b p+k e)-l e^{2}\right]_{\alpha}^{U} \\
\text { s.t. } \quad \operatorname{Cr}\{a-b p+k e<0\}=0 \\
p \geq w .
\end{array}
$$

The $\alpha$-optimistic value of the retailer's profit is

$$
\left[\pi_{r}(w, p, e)\right]_{\alpha}^{U}=(p-w)\left(a_{\alpha}^{U}-b_{\alpha}^{L} p+k_{\alpha}^{U} e\right)-l_{\alpha}^{U} e^{2} .
$$

The first and second partial derivatives of $\left[\pi_{r}(w, p, e)\right]_{\alpha}^{U}$ with respect to $(p, e)$ can be obtained as

$$
\begin{gathered}
\frac{\partial\left[\pi_{r}(w, p, e)\right]_{\alpha}^{U}}{\partial p}=-2 b_{\alpha}^{L} p+k_{\alpha}^{U} e+b_{\alpha}^{L} w+a_{\alpha}^{U}, \\
\frac{\partial\left[\pi_{r}(w, p, e)\right]_{\alpha}^{U}}{\partial e}=k_{\alpha}^{U} p-2 l_{\alpha}^{L} e-k_{\alpha}^{U} w, \\
\frac{\partial^{2}\left[\pi_{r}(w, p, e)\right]_{\alpha}^{U}}{\partial^{2} p}=-2 b_{\alpha}^{L}, \\
\frac{\partial^{2}\left[\pi_{r}(w, p, e)\right]_{\alpha}^{U}}{\partial e^{2}}=-2 l_{\alpha}^{L}, \\
\frac{\partial^{2}\left[\pi_{r}(w, p, e)\right]_{\alpha}^{U}}{\partial p \partial e}=\frac{\partial^{2}\left[\pi_{r}(w, p, e)\right]_{\alpha}^{U}}{\partial e \partial p}=k_{\alpha}^{U} .
\end{gathered}
$$

If $4 b_{\alpha}^{L} l_{\alpha}^{L}>\left(k_{\alpha}^{U}\right)^{2}$, the Hessian matrix is negative definite. Let (19) be equal to zero; we can obtain (16).
Theorem 4. In the MS model, the optimal wholesale price $w_{m}^{*}$ is

$$
w_{m}^{*}=\frac{a_{\alpha}^{U}+b_{\alpha}^{L} c_{\alpha}^{L}}{2 b_{\alpha}^{L}}
$$

provided that $\operatorname{Cr}\left\{\left(a_{\alpha}^{U}+b_{\alpha}^{L} c_{\alpha}^{L}\right) /\left(2 b_{\alpha}^{L}\right)-c<0\right\}=0$.

Proof. From (1), (3), and (16), it can be obtained that

$$
\left[\pi_{m}\left(w, p^{*}(w), e^{*}(w)\right)\right]_{\alpha}^{U}=\frac{2 b_{\alpha}^{L} l_{\alpha}^{L}\left(w-2 c_{\alpha}^{L}\right)\left(a_{\alpha}^{U}-b_{\alpha}^{L} w\right)}{4 b_{\alpha}^{L} l_{\alpha}^{L}-\left(k_{\alpha}^{U}\right)^{2}},
$$

the first and second order derivatives of which with respect to $w$ are

$$
\begin{gathered}
\frac{\mathrm{d}\left[\pi_{m}\left(w, p^{*}(w), e^{*}(w)\right)\right]_{\alpha}^{U}}{\mathrm{~d} w}=\frac{2 b_{\alpha}^{L} l_{\alpha}^{L}\left(a_{\alpha}^{U}+b_{\alpha}^{L} l_{\alpha}^{L}-2 b_{\alpha}^{L} w\right)}{4 b_{\alpha}^{L} l_{\alpha}^{L}-\left(k_{\alpha}^{U}\right)^{2}}, \\
\frac{\mathrm{d}^{2}\left[\pi_{m}\left(w, p^{*}(w), e^{*}(w)\right)\right]_{\alpha}^{U}}{\mathrm{~d} w^{2}}=\frac{-4\left(b_{\alpha}^{L}\right)^{2} l_{\alpha}^{L}}{4 b_{\alpha}^{L} l_{\alpha}^{L}-\left(k_{\alpha}^{U}\right)^{2}} .
\end{gathered}
$$

Hence, $\left[\pi_{m}\left(w, p^{*}(w), e^{*}(w)\right)\right]_{\alpha}^{U}$ is a convex function with respect to $w$ provided that $4 b_{\alpha}^{L} l_{\alpha}^{L}>\left(k_{\alpha}^{U}\right)^{2}$. By letting (23) be equal to zero and solving for $w$, (21) can be obtained.

Theorem 5. In the MS model, given the wholesale price $w^{*}$ made earlier by the manufacturer, the retailer's optimal decisions of $p^{*}$ and $e^{*}$ satisfy

$$
\begin{gathered}
p_{m}^{*}=\frac{2 b_{\alpha}^{L} l_{\alpha}^{L}\left(3 a_{\alpha}^{U}+b_{\alpha}^{L} c_{\alpha}^{L}\right)-\left(k_{\alpha}^{U}\right)^{2}\left(a_{\alpha}^{U}+b_{\alpha}^{L} c_{\alpha}^{L}\right)}{2 b_{\alpha}^{L}\left[4 b_{\alpha}^{L} l_{\alpha}^{L}-\left(k_{\alpha}^{U}\right)^{2}\right]}, \\
e_{m}^{*}=\frac{\left[a_{\alpha}^{U}-b_{\alpha}^{L} l_{\alpha}^{L}\right] k_{\alpha}^{U}}{8 b_{\alpha}^{L} l_{\alpha}^{L}-2\left(k_{\alpha}^{U}\right)^{2}} .
\end{gathered}
$$

Proof. Substituting (21) into (16), then (25) and (26) can be obtained.

Corollary 6. If selling effort is not considered, model (15) degenerates into

$$
\begin{array}{ll}
\max _{w} & {\left[\pi_{m}\left(w, p^{*}(w)\right]_{\alpha}^{U}=\left[(w-c)\left(a-b p^{*}(w)\right)\right]_{\alpha}^{U}\right.} \\
\text { s.t. } & \operatorname{Cr}\{w-c<0\}=0 \\
& p^{*} \text { solves } \\
& \max _{p} \quad\left[\pi_{r}(w, p)\right]_{\alpha}^{U}=[(p-w)(a-b p)]_{\alpha}^{U} \\
\text { s.t. } \quad & \operatorname{Cr}\{a-b p<0\}=0 \\
& p \geq w .
\end{array}
$$


The optimal wholesale price $w_{m}^{* *}$ and retail price $p_{m}^{* *}$ in case no selling effort corresponded to $w_{m}^{*}$ in (21) and $p_{m}^{*}$ in (25) are

$$
\begin{aligned}
& w_{m}^{* *}=\frac{a_{\alpha}^{U}+2 b_{\alpha}^{L} c_{\alpha}^{L}}{3 b_{\alpha}^{L}} \\
& p_{m}^{* *}=\frac{2 a_{\alpha}^{U}+b_{\alpha}^{L} c_{\alpha}^{L}}{3 b_{\alpha}^{L}}
\end{aligned}
$$

3.3. Retailer Leader Stackelberg (RS) Game Model. The third scenario arises in the markets where the retailer's size is larger compared to his manufacturer's. In this case, the retailer is the leader and the manufacturer is the follower, and the twoechelon RS model can be formulated as

$$
\begin{array}{ll}
\max _{(p, e)} & \max _{\bar{\pi}_{r}} \bar{\pi}_{r} \\
\text { s.t. } & \operatorname{Cr}\left\{\left(p-w^{*}(p, e)\right)(a-b p+k e)-l e^{2} \geq \bar{\pi}_{r}\right\} \geq \alpha \\
& \operatorname{Cr}\{a-b p+k e<0\}=0 \\
& p \geq w^{*}(p, e) \\
w^{*}(p, e) \text { solves } & \\
\max _{w} \quad \max _{\bar{\pi}_{m}} \bar{\pi}_{m} \\
\text { s.t. } \quad \operatorname{Cr}\left\{(w-c)(a-b p+k e) \geq \bar{\pi}_{m}\right\} \geq \alpha \\
\quad \operatorname{Cr}\{w-c<0\}=0 .
\end{array}
$$

Theorem 7. In the RS model, given $p$ and e made earlier by the retailer, the optimal wholesale price $w^{*}(p, e)$ is

$$
w^{*}(p, e)=\frac{a_{\alpha}^{U}+b_{\alpha}^{L} c_{\alpha}^{L}+k_{\alpha}^{U} e}{b_{\alpha}^{L}}-p,
$$

provided that $\operatorname{Cr}\left\{\left(a_{\alpha}^{U}+b_{\alpha}^{L} c_{\alpha}^{L}+k_{\alpha}^{U} e\right) / b_{\alpha}^{L}<p+c\right\}=0$.

Proof. Similar to the MS case, model (29) is equivalent to

$$
\begin{array}{ll}
\underset{(p, e)}{\max } & {\left[\left(p-w^{*}(p, e)\right)(a-b p+k e)-l e^{2}\right]_{\alpha}^{U}} \\
\text { s.t. } & \operatorname{Cr}\{a-b p+k e<0\}=0 \\
& p \geq w^{*}(p, e) \\
& w^{*} \text { solves } \\
& \max _{w} \quad\left[\pi_{m}(w, p, e)\right]_{\alpha}^{U}=[(w-c)(a-b p+k e)]_{\alpha}^{U} \\
& \text { s.t. } \quad \operatorname{Cr}\{w-c<0\}=0 .
\end{array}
$$

The $\alpha$-optimistic value of the manufacturer's profit is

$$
\left[\pi_{m}(w, p, e)\right]_{\alpha}^{U}=\left(w-c_{\alpha}^{L}\right)\left(a_{\alpha}^{U}-b_{\alpha}^{L} p+k_{\alpha}^{U} e\right) .
$$

Following from $p=w+m$, the first and second order derivatives of (32) with respect to $w$ can be obtained as

$$
\begin{gathered}
\frac{\mathrm{d}\left[\pi_{r}(w, p, e)\right]_{\alpha}^{U}}{\mathrm{~d} w}=a_{\alpha}^{U}-b_{\alpha}^{L} p+k_{\alpha}^{U} e-b_{\alpha}^{L}\left(w-c_{\alpha}^{L}\right), \\
\frac{\mathrm{d}^{2}\left[\pi_{r}(w, p, e)\right]_{\alpha}^{U}}{\mathrm{~d} w^{2}}=-2 b_{\alpha}^{L} .
\end{gathered}
$$

Hence, $\left[\pi_{m}(w)\right]_{\alpha}^{U}$ is a convex function with respect to $w$; by letting (33) be equal to zero and solving for $w$, (30) can be obtained.

Theorem 8. In the RS model, the optimal strategy of the retail price $p_{r}^{*}$ and the selling effort $e_{r}^{*}$ of the retailer are

$$
\begin{gathered}
p_{r}^{*}=\frac{6 a_{\alpha}^{U} l_{\alpha}^{L}+2 b_{\alpha}^{L} c_{\alpha}^{L} l_{\alpha}^{L}-c_{\alpha}^{L}\left(k_{\alpha}^{U}\right)^{2}}{8 b_{\alpha}^{L} l_{\alpha}^{L}-\left(k_{\alpha}^{U}\right)^{2}}, \\
e_{r}^{*}=\frac{\left(a_{\alpha}^{U}-b_{\alpha}^{L} c_{\alpha}^{L}\right) k_{\alpha}^{U}}{8 b_{\alpha}^{L} l_{\alpha}^{L}-\left(k_{\alpha}^{U}\right)^{2}}
\end{gathered}
$$

provided that $4 b_{\alpha}^{L} l_{\alpha}^{L}-\left(k_{\alpha}^{U}\right)^{2}>0$ and $\operatorname{Cr}\left\{a<\left(b\left(6 a_{\alpha}^{U} l_{\alpha}^{L}+\right.\right.\right.$ $\left.\left.\left.2 b_{\alpha}^{L} c_{\alpha}^{L} l_{\alpha}^{L}-c_{\alpha}^{L}\left(k_{\alpha}^{U}\right)^{2}\right)+k k_{\alpha}^{U}\left(a_{\alpha}^{U}-b_{\alpha}^{L} c_{\alpha}^{L}\right)\right) /\left(8 b_{\alpha}^{L} l_{\alpha}^{L}-\left(k_{\alpha}^{U}\right)^{2}\right)\right\}=0$.

Proof. From (1), (2), (4), and (30), it can be obtained that

$$
\begin{aligned}
& {\left[\pi_{r}\left(w^{*}(p, e), p, e\right)\right]_{\alpha}^{U}} \\
& \quad=\left(2 p-\frac{a_{\alpha}^{U}+b_{\alpha}^{L} c_{\alpha}^{L}+k_{\alpha}^{U} e}{b_{\alpha}^{L}}\right)\left(a_{\alpha}^{U}-b_{\alpha}^{L} p+k_{\alpha}^{U} e\right)-l_{\alpha}^{L} e^{2} .
\end{aligned}
$$

The first and second partial derivatives of $\left[\pi_{r}\left(w^{*}(p, e), p, e\right)\right]_{\alpha}^{U}$ with respect to $(p, e)$ can be obtained as

$$
\begin{gathered}
\frac{\partial\left[\pi_{r}\left(w^{*}(p, e), p, e\right)\right]_{\alpha}^{U}}{\partial p}=3 k_{\alpha}^{U} e+3 a_{\alpha}^{U}+b_{\alpha}^{L} c_{\alpha}^{L}-4 b_{\alpha}^{L} p \\
\frac{\partial\left[\pi_{r}\left(w^{*}(p, e), p, e\right)\right]_{\alpha}^{U}}{\partial e} \\
=\frac{k_{\alpha}^{U}}{b_{\alpha}^{L}}\left(3 b_{\alpha}^{L} p-2\left(k_{\alpha}^{U}+\frac{b_{\alpha}^{L} l_{\alpha}^{L}}{k_{\alpha}^{U}}\right) e-2 a_{\alpha}^{U}-b_{\alpha}^{L} c_{\alpha}^{L}\right) \\
\frac{\partial^{2}\left[\pi_{r}\left(w^{*}(p, e), p, e\right)\right]_{\alpha}^{U}}{\partial p^{2}}=-4 b_{\alpha}^{L}, \\
\frac{\partial^{2}\left[\pi_{r}\left(w^{*}(p, e), p, e\right)\right]_{\alpha}^{U}}{\partial e^{2}}=\frac{-2\left(k_{\alpha}^{U}+b_{\alpha}^{L} l_{\alpha}^{L}\right) k_{\alpha}^{U}}{b_{\alpha}^{L}} \\
\frac{\partial^{2}\left[\pi_{r}\left(w^{*}(p, e), p, e\right)\right]_{\alpha}^{U}}{\partial p \partial e}=\frac{\partial^{2}\left[\pi_{r}\left(w^{*}(p, e), p, e\right)\right]_{\alpha}^{U}}{\partial e \partial p}=3 k_{\alpha}^{U} .
\end{gathered}
$$

If $4 b_{\alpha}^{L} l_{\alpha}^{L}>\left(k_{\alpha}^{U}\right)^{2}$, the Hessian matrix is negative definite. Let (38) be equal to zero; we can obtain (35) and (36). 
Theorem 9. In the RS model, given $\left(p_{r}^{*}, e_{r}^{*}\right)$ made earlier by the retailer, the optimal wholesale price $w_{r}^{*}$ is

$$
w_{r}^{*}=\frac{2\left(a_{\alpha}^{U}+b_{\alpha}^{L} c_{\alpha}^{L}\right) l_{\alpha}^{L}-c_{\alpha}^{L}\left(k_{\alpha}^{U}\right)^{2}}{8 b_{\alpha}^{L} c_{\alpha}^{L}-\left(k_{\alpha}^{U}\right)^{2}} .
$$

Proof. Substituting (35) and (36) into (30), then (40) can be obtained.

Corollary 10. If selling effort is not considered, the optimal wholesale price $w_{r}^{* *}$ and retail price $p_{r}^{* *}$ in case no selling effort corresponded to $w_{r}^{*}$ in (40) and $p_{r}^{*}$ in (35) are

$$
\begin{aligned}
& w_{r}^{* *}=\frac{a_{\alpha}^{U}+3 b_{\alpha}^{L} c_{\alpha}^{L}}{4 b_{\alpha}^{L}}, \\
& p_{r}^{* *}=\frac{3 a_{\alpha}^{U}+b_{\alpha}^{L} c_{\alpha}^{L}}{4 b_{\alpha}^{L}} .
\end{aligned}
$$

3.4. Nash Game (NG) Model. The fourth scenario models a market in which there are relatively small to medium-sized manufacturers and retailers. In this case, each part of the supply chain system has equal bargaining power and makes their decisions simultaneously. Therefore, the two-echelon NG model can be formulated as

$$
\begin{array}{ll}
\max _{(p, e)} & \max _{\bar{\pi}_{r}} \bar{\pi}_{r} \\
\max _{w} & \max _{\bar{\pi}_{m}} \bar{\pi}_{m} \\
\text { s.t. } & \operatorname{Cr}\left\{(p-w)(a-b p+k e)-l e^{2} \geq \bar{\pi}_{r}\right\} \geq \alpha \\
& \operatorname{Cr}\left\{(w-c)(a-b p+k e) \geq \bar{\pi}_{m}\right\} \geq \alpha \\
& \operatorname{Cr}\{a-b p+k e<0\}=0 \\
& \operatorname{Cr}\{w-c<0\}=0 \\
& p \geq w .
\end{array}
$$

Theorem 11. In the NG model, the respective optimal strategies chosen by the manufacturer and the retailer can be derived as

$$
\begin{gathered}
w_{n}^{*}=\frac{2\left(a_{\alpha}^{U}+2 b_{\alpha}^{L} c_{\alpha}^{L}\right) l_{\alpha}^{L}-c_{\alpha}^{L}\left(k_{\alpha}^{U}\right)^{2}}{6 b_{\alpha}^{L} l_{\alpha}^{L}-\left(k_{\alpha}^{U}\right)^{2}} \\
p_{n}^{*}=\frac{4\left(a_{\alpha}^{U}+b_{\alpha}^{L} c_{\alpha}^{L}\right) l_{\alpha}^{L}-c_{\alpha}^{L}\left(k_{\alpha}^{U}\right)^{2}}{6 b_{\alpha}^{L} l_{\alpha}^{L}-\left(k_{\alpha}^{U}\right)^{2}} \\
e_{n}^{*}=\frac{\left(a_{\alpha}^{U}-b_{\alpha}^{L} c_{\alpha}^{L}\right) k_{\alpha}^{U}}{6 b_{\alpha}^{L} l_{\alpha}^{L}-\left(k_{\alpha}^{U}\right)^{2}}
\end{gathered}
$$

provided that $\operatorname{Cr}\left\{a<b p_{n}^{*}+k e_{n}^{*}\right\}=0$ and $\operatorname{Cr}\left\{w_{n}^{*}<c\right\}=0$.
Proof. Obviously, model (42) is equivalent to the following model:

$$
\begin{array}{ll}
\max _{(p, e)} & {\left[\pi_{r}(w, p, e)\right]_{\alpha}^{U}=\left[(p-w)(a-b p+k e)-l e^{2}\right]_{\alpha}^{U}} \\
\max _{w} & {\left[\pi_{m}(w, p, e)\right]_{\alpha}^{U}=[(w-c)(a-b p+k e)]_{\alpha}^{U}} \\
\text { s.t. } & \operatorname{Cr}\{a-b p+k e<0\}=0 \\
& \operatorname{Cr}\{w-c<0\}=0 \\
& p \geq w .
\end{array}
$$

From the MS model, given the wholesale prices $w$ made earlier by the manufacturer, the retailer's optimal strategy satisfies (16), and from the RS model, given retail optimal strategy $(p, e)$, the optimal wholesale price satisfies (30). Then, solving (16), and (30) simultaneously yields the Nash decision solution (43)-(45).

Corollary 12. When selling effort is not considered, the optimal wholesale price $w_{n}^{* *}$ and retail price $p_{n}^{* *}$ in case no selling effort corresponded to $w_{n}^{*}$ in (43) and $p_{n}^{*}$ in (44) are

$$
\begin{aligned}
& w_{n}^{* *}=\frac{a_{\alpha}^{U}-2 b_{\alpha}^{L} c_{\alpha}^{L}}{3 b_{\alpha}^{L}}, \\
& p_{n}^{* *}=\frac{a_{\alpha}^{U}-b_{\alpha}^{L} c_{\alpha}^{L}}{b_{\alpha}^{L}} .
\end{aligned}
$$

\section{Numerical Example}

In this section, a numerical example is provided to compare the results established in the above four different decision scenarios and to analyze the effects of the bargaining power on the channel prices and optimal profits.

Consider the case that the manufacturing cost $c$ is in medium level ( $c$ is about 2), the market base $a$ is in high level ( $a$ is about 700), and the price elastic coefficient $b$, the effort elastic coefficient $k$, and the effort cost coefficient $l$ are in very sensitive level (i.e., $b$ is about $40, k$ is about 8 , and $l$ is about 3 ). The relationship between linguistic expressions and triangular fuzzy variables for manufacturing cost, market base, price elasticity, and selling effort elasticity is often determined by experts' experience, as shown in Table 1 (for more references about the relationship between linguistic expression and fuzzy variable see $[27,28])$.

From Table 1, we can obtain that the triangular fuzzy variables are $c=(1,2,3), a=(600,700,800), b=(30,40,50)$, $k=(7,8,9)$, and $l=(2,3,4)$. The respective $\alpha$ critical values are $a_{\alpha}^{U}=800-100 \alpha, b_{\alpha}^{L}=30+10 \alpha, c_{\alpha}^{L}=1+\alpha, k_{\alpha}^{U}=9-\alpha$, and $l_{\alpha}^{L}=2+\alpha$. From the results derived in the above four scenarios, namely, models of CD, MS, RS, and NG, the optimal retail prices, wholesale prices, selling efforts, profits of the system, profits of the manufacturer, and profits of the retailer can be calculated as shown in Tables 2 and 3 with a confidence value $\alpha=0.8$.

Firstly, the optimal retail prices, wholesale prices, and selling efforts are compared according to the results in Table 2. 
TABLE 1: Relationship between linguistic expression and triangular fuzzy variable.

\begin{tabular}{lcc}
\hline & Linguistic expression & Triangular fuzzy variable \\
\hline \multirow{2}{*}{$c$} & Low (about 1) & $(0.5,1,1.5)$ \\
& Medium (about 2) & $(1.5,2,2.5)$ \\
& High (about 3) & $(2.5,3,3.5)$ \\
\hline \multirow{2}{*}{$a$} & Large (about 700) & $(600,700,800)$ \\
& Small (about 500) & $(400,500,600)$ \\
\hline \multirow{2}{*}{$k$} & Very sensitive (about 40) & $(30,40,50)$ \\
& Sensitive (about 20) & $(10,20,30)$ \\
\hline \multirow{2}{*}{$k$} & Very sensitive (about 8$)$ & $(7,8,9)$ \\
& Sensitive (about 6) & $(5,6,7)$ \\
\hline & Very sensitive (about 3) & $(2,3,4)$ \\
& Sensitive (about 1) & $(0.5,1,1.5)$ \\
\hline
\end{tabular}

TABLE 2: Optimal retail prices, wholesale prices, and efforts.

\begin{tabular}{lccccc}
\hline & $p^{*}$ & $p^{* *}$ & $w^{*}$ & $w^{* *}$ & $e^{*}$ \\
\hline CD & 11.98 & 10.37 & & & 14.91 \\
MS & 15.46 & 13.23 & 9.47 & 7.52 & 7.45 \\
RS & 15.76 & 14.66 & 6.45 & 6.09 & 6.82 \\
NG & 15.41 & 13.23 & 8.19 & 7.52 & 9.35 \\
\hline
\end{tabular}

TABLE 3: Optimal profits.

\begin{tabular}{lcccccc}
\hline & $\bar{\pi}_{c}^{*}$ & $\bar{\pi}_{c}^{* *}$ & $\bar{\pi}_{m}^{*}$ & $\bar{\pi}_{m}^{* *}$ & $\bar{\pi}_{r}^{*}$ & $\bar{\pi}_{r}^{* *}$ \\
\hline CD & 3317 & 2793 & & & & \\
MS & 2488 & 2483 & 1485 & 1242 & 1003 & 1241 \\
RS & 2340 & 2095 & 823 & 698 & 1516 & 1397 \\
NG & 2627 & 2482 & 1348 & 1241 & 1279 & 1241 \\
\hline
\end{tabular}

The retail price under the RS case is the highest, followed by MS and then the NG and CD games; the wholesale price in the case of MS is the highest, followed by NG and then RS; the selling effort in the case of CD is the highest, followed by NG, MS, and then RS.

Secondly, the optimal profits of the whole supply chain, the manufacturer, and the retailer are compared according to the results in Table 3. The profit in the case of CD is the highest, followed by NG and then MS and RS; under the three decentralized decision cases, the manufacturer gains the largest profit in the case of MS, followed by NG and then RS. Meanwhile, the retailer gains the largest profits in RS game, followed by NG and then MS.

Thirdly, no matter what decision case is, the optimal retail prices and wholesale prices in the case of considering selling effort are, respectively, larger than those of no selling efforts; the optimal profits of the manufacturer, the retailer, and the whole supply chain system in the case of considering selling effort are, respectively, larger than those of no selling effort, except the profit of the retailer in the case that the manufacturer is the leader.
Based on the above analysis, insights can be obtained as follows.

(1) Compared with the three decentralized decision cases, the whole supply chain system obtains larger profit under the centralized decision case.

(2) Comparing among the three decentralized decision cases, the whole supply chain system gains the largest profit in Nash game scenario. However, both the manufacturer and the retailer have an incentive to play the leader's role for the leader holds advantage in getting the relatively higher profit.

(3) No matter what decision case is, selling effort makes both the retail price and the wholesale price larger than those without selling effort.

(4) No matter what decision case is, the profits of both the whole supply chain system and the manufacturer in the case of considering selling effort are, respectively, larger than those of no selling effort. However, in the manufacturer leader Stackelberg game case, the profit of the retailer in the case of considering selling effort is less than that of no selling effort. This means that the retailer may hesitate to make effort to increase sales when the manufacturer is the leader.

\section{Conclusion}

The main contribution of this paper is that an optimal pricing and selling effort decision problem has been formulated under a two-echelon supply chain facing uncertain demand that is sensitive to both selling effort and retail price in a fuzzy environment. Based on different market structures, four chance constraint programming models were developed with fuzzy customer demands, fuzzy manufacturing costs, and fuzzy selling effort costs, which extend the classical supply chain models with stochastic (or deterministic) demand and crisp costs given in the past. By using fuzzy theory and game theory, the analytical equilibrium solutions of the pricing and selling effort strategies of both the manufacturer and the retailer were derived by analytical method. Some analyse about the results were established which present insights into the economic behavior of firms and can be served as the basis for empirical study in the future.

Our results are based upon some assumptions about the demand function and selling cost for analytical convenience. Thus, there are possible extensions; for example, different or more general forms of the demand function can be used to analyze the problem, and the supply chain with more than one manufacturer, and retailer and over multiple periods can also be considered.

\section{Conflict of Interests}

The authors declare that there is no conflict of interests regarding the publication of this paper. 


\section{Acknowledgments}

This work was partly supported by Tianjin Key Lab of Intelligent Computing and Novel Software Technology, Key Laboratory of Computer Vision and System, Ministry of Education, and the National Science Foundation of China under Grants nos. 61202381, 61170301, and 61201234 and by an Education commission Project under Grant no. 20110801. The authors would like to thank the anonymous referee experts for the amendments and valuable advice to perfect the work.

\section{References}

[1] M. A. Lariviere and E. L. Porteus, "Selling to the newsvendor: an analysis of price-only contracts," Manufacturing and Service Operations Management, vol. 3, no. 4, pp. 293-305, 2001.

[2] T. A. Taylor, "Supply chain coordination under channel rebates with sales effort effects," Management Science, vol. 48, no. 8, pp. 992-1007, 2002.

[3] G. P. Cachon and M. A. Lariviere, "Supply chain coordination with revenue-sharing contracts: strengths and limitations," Management Science, vol. 51, no. 1, pp. 30-44, 2005.

[4] H. I. Mesak, H. Zhang, and J. M. Pullis, "On optimal service capacity allocation policy in an advance selling environment in continuous time," European Journal of Operational Research, vol. 203, no. 2, pp. 505-512, 2010.

[5] H. Krishnan, R. Kapuscinski, and D. A. Butz, "Coordinating contracts for decentralized supply chains with retailer promotional effort," Management Science, vol. 50, no. 1, pp. 48-63, 2004.

[6] D. Dash Wu, "Bargaining in supply chain with price and promotional effort dependent demand," Mathematical and Computer Modelling, vol. 58, no. 9-10, pp. 1659-1669, 2013.

[7] G. P. Cachon, "Stock wars: inventory competition in a twoechelon supply chain with multiple retailers," Operations Research, vol. 49, no. 5, pp. 658-674, 2001.

[8] F. Hu, C.-C. Lim, Z. Lu, and X. Sun, "Coordination in a singleretailer two-supplier supply chain under random demand and random supply with disruption," Discrete Dynamics in Nature and Society, vol. 2013, Article ID 484062, 12 pages, 2013.

[9] A. H. L. Lau and H.-S. Lau, "Some two-echelon supply-chain games: Improving from deterministic- symmetric-information to stochastic-asymmetric-information models," European Journal of Operational Research, vol. 161, no. 1, pp. 203-223, 2005.

[10] L. A. Zadeh, "Fuzzy sets," Information and Control, vol. 8, no. 3, pp. 338-353, 1965.

[11] B. Liu and Y.-K. Liu, "Expected value of fuzzy variable and fuzzy expected value models," IEEE Transactions on Fuzzy Systems, vol. 10, no. 4, pp. 445-450, 2002.

[12] H.-J. Zimmermann, "Applications of fuzzy set theory to mathematical programming," Information Sciences, vol. 36, no. 1-2, pp. 29-58, 1985.

[13] D. Petrovic, Y. Xie, K. Burnham, and R. Petrovic, "Coordinated control of distribution supply chains in the presence of fuzzy customer demand," European Journal of Operational Research, vol. 185, no. 1, pp. 146-158, 2008.

[14] I. Erol, S. Sencer, and R. Sari, "A new fuzzy multi-criteria framework for measuring sustainability performance of a supply chain," Ecological Economics, vol. 70, no. 6, pp. 1088-1100, 2011.

[15] J. Wei, G. Pang, Y. Liu, and Q. Ma, "Pricing decisions of a twoechelon supply chain in fuzzy environment," Discrete
Dynamics in Nature and Society, vol. 2013, Article ID 971504, 11 pages, 2013.

[16] J. Zhao, W. Liu, and J. Wei, "Pricing and remanufacturing decisions of a decentralized fuzzy supply chain," Discrete Dynamics in Nature and Society, vol. 2013, Article ID 986704, 10 pages, 2013.

[17] S.-J. Chuu, "Interactive group decision-making using a fuzzy linguistic approach for evaluating the flexibility in a supply chain," European Journal of Operational Research, vol. 213, no. 1, pp. 279-289, 2011.

[18] J. Wei and J. Zhao, "Pricing decisions with retail competition in a fuzzy closed-loop supply chain," Expert Systems with Applications, vol. 38, no. 9, pp. 11209-11216, 2011.

[19] J. Zhao, W. Tang, and J. Wei, "Pricing decision for substitutable products with retail competition in a fuzzy environment," International Journal of Production Economics, vol. 135, no. 1, pp. 144-153, 2012.

[20] J. Zhao, W. Tang, R. Zhao, and J. Wei, "Pricing decisions for substitutable products with a common retailer in fuzzy environments," European Journal of Operational Research, vol. 216, no. 2, pp. 409-419, 2012.

[21] L. Wang, H. Qu, Y. Li, and J. He, "Modeling and optimization of stochastic joint replenishment and delivery scheduling problem with uncertain costs," Discrete Dynamics in Nature and Society, vol. 2013, Article ID 657465, 12 pages, 2013.

[22] A. Charnes and W. Cooper, "Chance-constrained programming," Management Science, vol. 6, no. 1, pp. 73-79, 1959.

[23] B. Liu and K. Iwamura, "Chance constrained programming with fuzzy parameters," Fuzzy Sets and Systems, vol. 94, no. 2, pp. 227-237, 1998.

[24] J. Gao and B. Liu, "Fuzzy multilevel programming with a hybrid intelligent algorithm," Computers and Mathematics with Applications, vol. 49, no. 9-10, pp. 1539-1548, 2005.

[25] C. Zhou, R. Zhao, and W. Tang, "Two-echlon supply chain games in a fuzzy environment," Computers and Industrial Engineering, vol. 55, no. 2, pp. 390-405, 2008.

[26] C. Wang, W. Tang, and R. Zhao, "On the continuity and convexity analysis of the expected value function of a fuzzy mapping," Journal of Uncertain Systems, vol. 1, no. 2, pp. 148-160, 2007.

[27] L. A. Zadeh, "The concept of a linguistic variable and its application to approximate reasoning-I," Information Sciences, vol. 8, no. 3, pp. 199-249, 1975.

[28] J. Zhao, W. Tang, and J. Wei, "Pricing decision for substitutable products with retail competition in a fuzzy environment," International Journal of Production Economics, vol. 135, no. 1, pp. 144-153, 2012. 


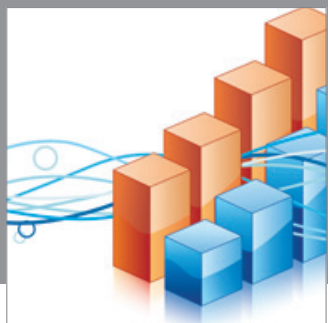

Advances in

Operations Research

mansans

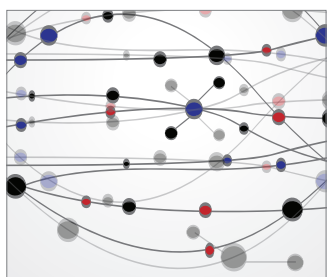

The Scientific World Journal
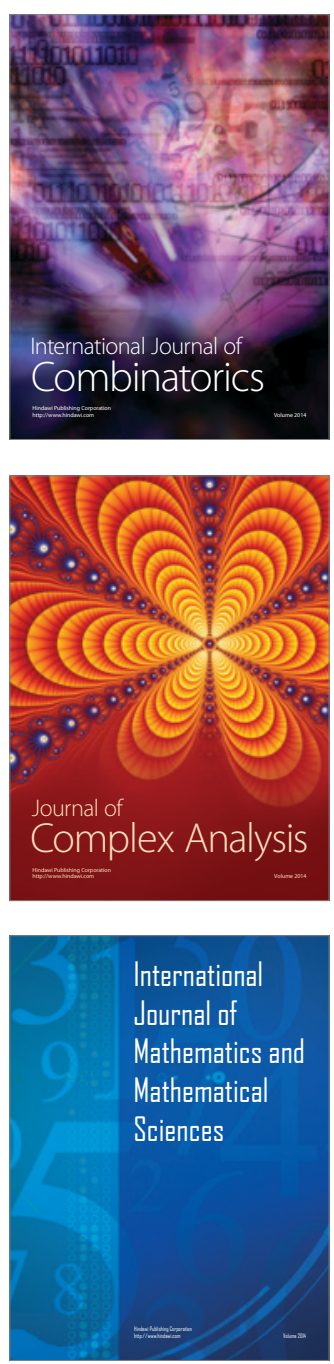
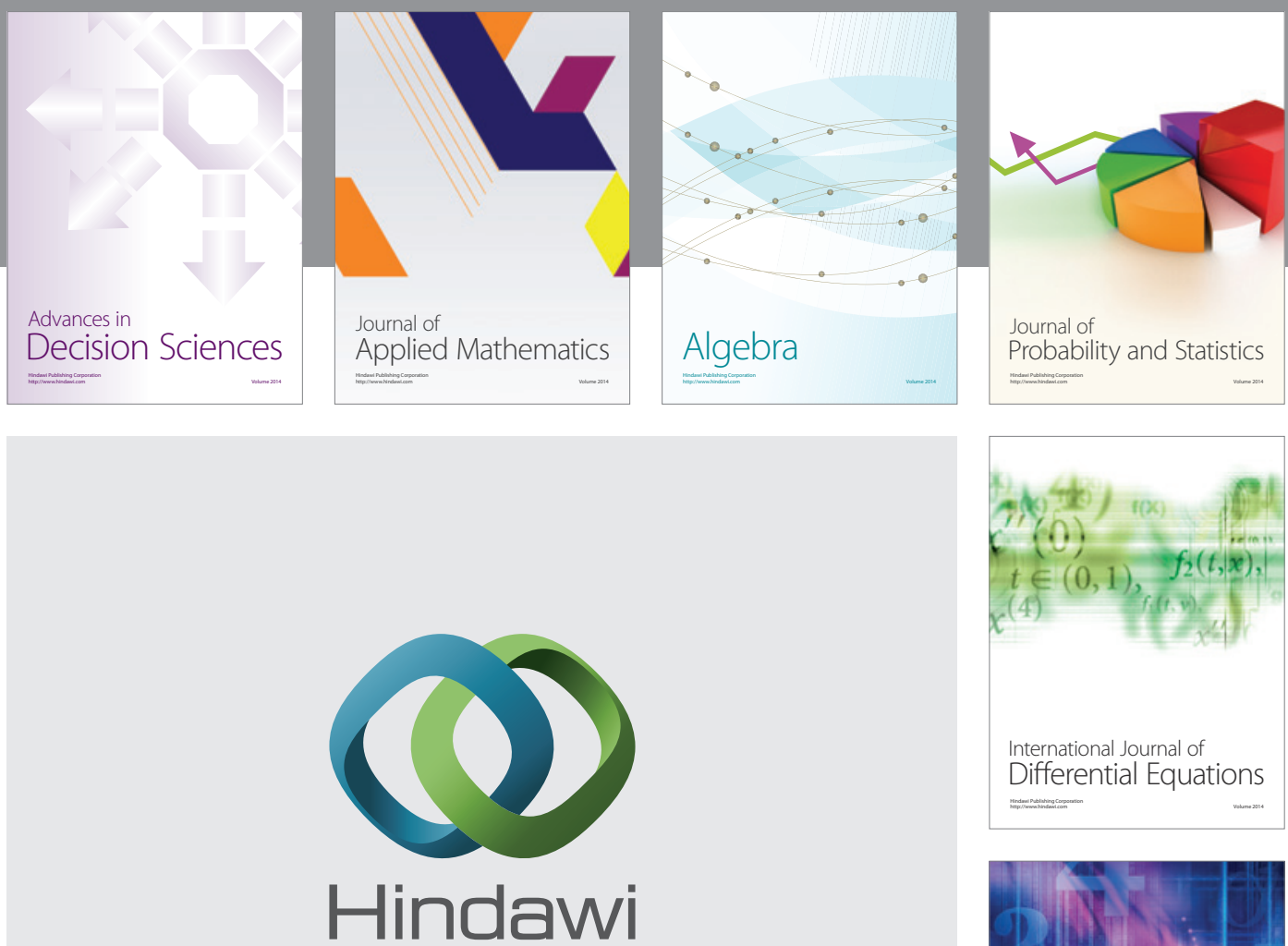

Submit your manuscripts at http://www.hindawi.com
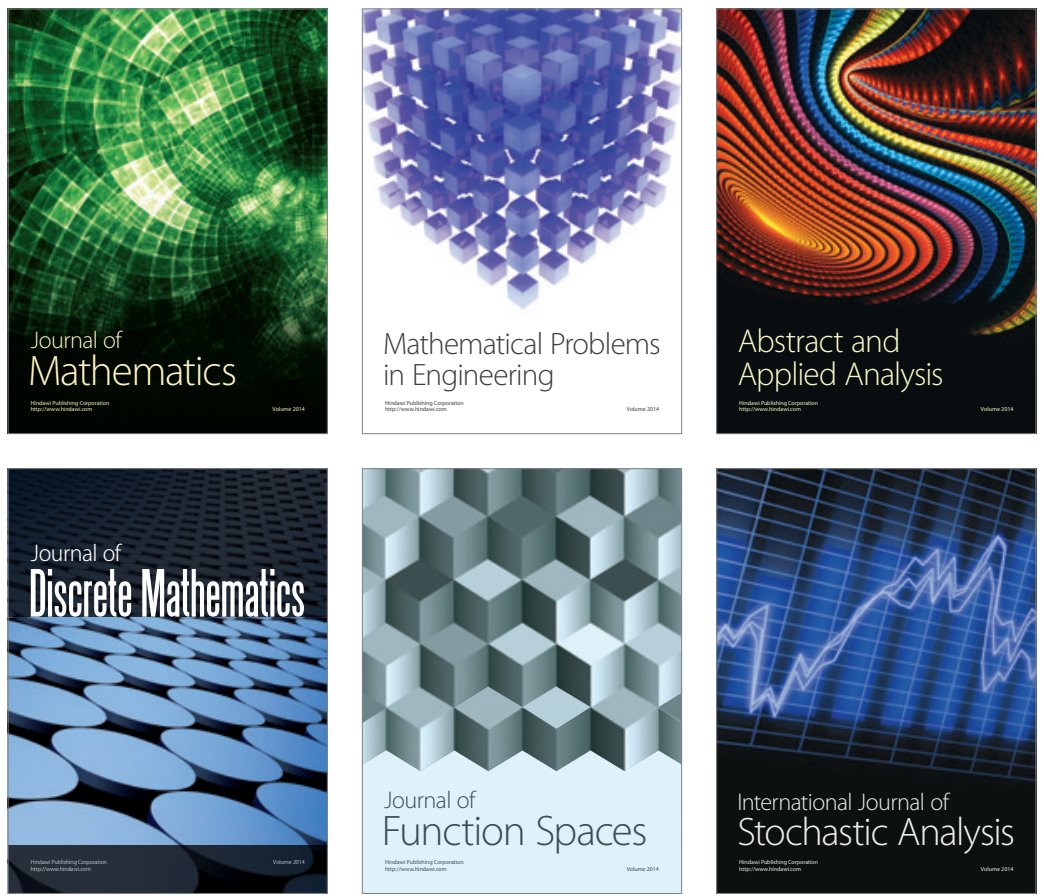

Journal of

Function Spaces

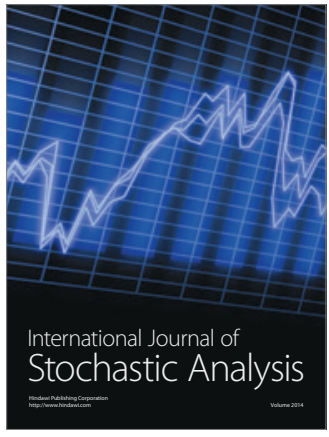

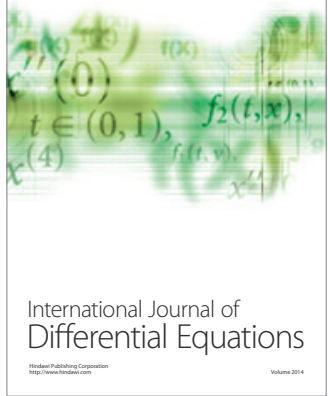
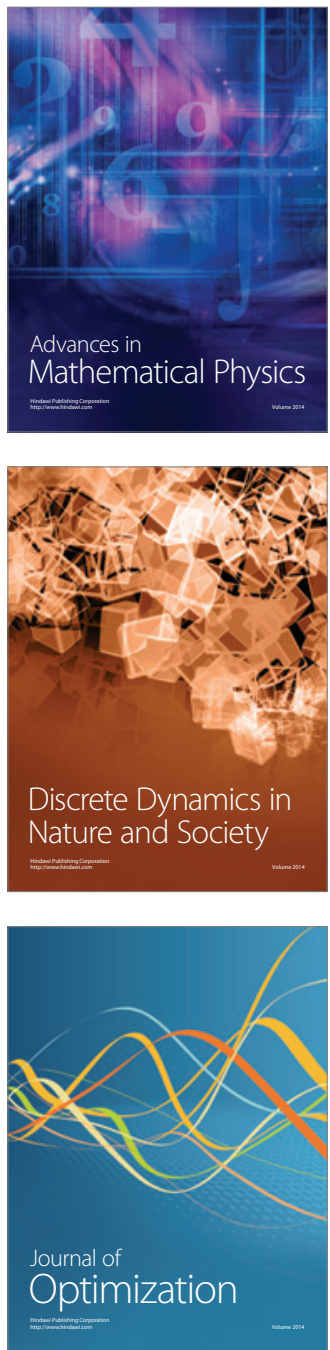